\title{
Studies on Isolation and Characterization of Antibiotic Producing Microorganisms from Industrial Waste Soil Sample
}

\author{
Atul Pratap Singh ${ }^{1}$, R.B. Singh ${ }^{2}$ and Sanjay Mishra ${ }^{1, *}$ \\ ${ }^{1}$ School of Biotechnology, IFTM University, Lodhipur Rajput, Delhi Road (NH-24), Moradabad 244001, U.P., India \\ ${ }^{2}$ Halberg Hospital \& Research Center, Civil Lines, Moradabad 244 001, U.P., India
}

\begin{abstract}
Antibiotics are one of the most important commercially exploited secondary metabolites produced by the bacteria and employed in a wide range. Most of the antibiotic producers used today are the soil microbes. Fungal strains and streptomyces members are extensively used in industrial antibiotic production. Bacteria are easy to isolate, culture, maintain and to improve their strains. Microbes are omni present and exist in a competitive environment. Bacillus species being the predominant soil bacteria because of their resistant endospore formation and production of vital antibiotics like bacitracin etc. are always found inhibiting the growth of the other organisms. In the present paper a soil bacterium with the antibiotic activity was screened and studied for morphological characters probably providing valuable information about the strain. The inhibitory activity of the organism was checked against some of the important opportunistic microbial flora and inoculated into an appropriate designed media depending on the bacterial requirements, and incubated for 48 hrs at $37^{\circ} \mathrm{C}$. The produced compound was extracted by solvent extraction and assayed for its activity. Enhancement in the antibiotic production was studied under various parameters like temperature, $\mathrm{pH}$, carbon source concentration, and sodium nitrate concentration, probably helping in the industrial production. The extracted substance was found effective against the gram positive endospore forming bacilli and gram positive cocci. Though a large list of antibiotics are known to be commercially available, the search for the most potential one is still on, and this work may provide some potential information on the antibiotic production and the control of microbial strains.
\end{abstract}

Keywords: Collection of soil samples, Isolation methods for bacterial and fungal spp, Kirby-Bauer method, Disk method, Dilutions, Bio-chemical characteristics and media preparation.

\section{INTRODUCTION}

Antibiotics are the best known products of actinomycete. Over 5,000 antibiotics have been identified from the cultures of Gram-positive and Gram-negative organisms, and filamentous fungi, but only about 100 antibiotics have been commercially used to treat human, animal and plant diseases [1]. The genus, Streptomycete, is responsible for the formation of more than $60 \%$ of known antibiotics while a further $15 \%$ are made by a number of related Actinomycetes, Micromonospora, Actinomadura, Streptoverticillium and Thermoactinomycetes. Antibiotics, because of their industrial importance, are the best known products of actinomycetes [2-4]. The actinomycetes produce an enormous variety of bioactive molecules, e.g., antimicrobial compounds. One of the first antibiotics used is streptomycin produced by Streptomycin griseus.

On the whole, the last 55 years have seen the discovery of more than 12,000 antibiotics [4,5].

The actinomycetes yielded about $70 \%$ of these, and the remaining $30 \%$ are products of filamentous fungi and nonactinomycete bacteria [6,7]. Most of the bioactive com-

*Address correspondence to this author at the School of Biotechnology, IFTM University, Lodhipur Rajput, Delhi Road (NH-24). Moradabad 244 001, U.P., India; Tel: +91-591-2360817, +91-9837096059;

Fax: +91-591-2360818; E-mail: sanjaymishra@iftmuniversity.ac.in pounds from actinomycete sort into several major structural classes such as amino glycosides (e.g., streptomycin and kanamycin), ansamycins (e.g., rifampin), anthracyclines (e.g., doxorubicin), b-lactam (cephalosporins), macrolides (e.g., erythromycin), and tetracycline. Besides, the use of microorganisms (fungi and bacteria); which serve as probiotics, antibiotics, enzymes and ensiling have constituted methods of enrichment of non-digestible feedstuffs and those imbued with anti-nutritive factors. In poultry, small quantities of tannins in the diet were found to have caused adverse effects, while the inclusion of additional proteins or amino acids into the diets may alleviate the effects of tannins [8]. Decrease methionine availability could increase the toxicity of cyanogenic glycosides; because methionine is involved in the detoxification of cyanide via methylation to thiocyanate [8]. Essential mineral elements, namely, magnesium, sodium, potassium, phospohorus and calcium are as important as amino acids and vitamins in maintenance of life, wellbeing and production [9]. Minerals are essential for regulating and building the living and aid in fighting depression [10-13]. Phosphorus and calcium are closely associated in metabolism, particularly in bone formation; phosphorus plays a critical role in the maintenance of acid-base balance, while calcium is essential. The main objective of the present investigation was to study the Isolation of antibiotic producing microbes (Bacterial and Fungal Isolates) ant their biochemical characterization from Industrial waste Soil as well as agricultural soil compost - Farmyard manure. 


\section{MATERIALS AND METHODS}

Antimicrobial susceptibility testing methods were divided into types based on the principle applied in each system. They include (a) Diffusion; (b) Kerby-Bauer method/Disk method; (c) Dilution (Broth dilution, Agar dilution) ; (d) Minimum Inhibitory Concentration; (e) Diffusion and dilution; (f) E test method.

The efficacy of various antibiotic agents against a range of gram positive and gram negative microbial strains was assessed through measurement of zones of inhibition [1417]. Dilution susceptibility testing methods were used to determine the minimal concentration of antimicrobial to inhibit or kill the microorganism [18-20]. Nutrient agar medium was prepared and sterilized follwed by proper pouring into Petri plates under aseptic conditions in a Laminar air flow. The Petri plates were kept for setting of medium for some time. The supernatant of production medium was collected and stored at $4{ }^{\circ} \mathrm{C}$. Antibiotic activity was assayed for the supernatants. Using Whatman paper discs were prepared and immersed in vials and let them to stand for 30 min. E.coli and Pseudomonas cultures were aspirated out. The cultures were swabbed on Petri plates followed by a proper placement of the antibiotic discs on the nutrient agar medium using [21, 22]. Further, these Petri plates were incubated overnight without inverting at optimum temperature of $37{ }^{0} \mathrm{C}$ for 24 hours. Diffusion tests were used to determine the susceptibility of organisms isolated from soil samples of industrial waste areas.

\section{Isolation of Antibiotic Producers Soil Microbes}

Thirty $\mathrm{ml}$ of normal saline was prepared and distributed equally into 3 test tubes, appropriate dilutions performed, and sterilized [23]. One gm of soil samplewas weighed and added into the stock test tube with $10 \mathrm{ml}$ of saline under sterile conditions., vortexed for 2 -3 mins, and allowed to stand for $2 \mathrm{~min}$. One $\mathrm{ml}$ of sample from stock was transferred appropriately and shaken gently [24]. Finally, $0.5 \mathrm{ml}$ of sample was collected from the dilution test tubes and spread plated. The plates were inverted and incubated over night at $37^{\circ} \mathrm{C}$ [25].

\section{Screening of the Soil}

Eight actinomycetes were isolated from the soil samples [26]. They had pinpoint colonies with zone of inhibition. The presence of relatively large populations of actinomycetes in the soil samples of waste soil samples indicates that the source is an eminently suitable ecosystem. Pertinent details of the soil samples and the actinomycetes.

\section{Identification of Soil Bacterium from Secondary Cultures}

Nutrient agar medium with $1 \% \mathrm{CaCO} 3$ was prepared and sterilized [27]. The media was allowed to cool to 50-600c and poured into the sterilized Petri plates and allowed to solidify. Isolated colonies from slant culture was selected and taken carefully and streaked on the solidified medium in the Petri plates. The Petri plates were incubated at $37^{\circ} \mathrm{C}$ overnight [28].

\section{Biochemical Characteristics of Antibiotic Producing Microbes}

The isolate was biochemically characterized according to the Bergey's Manual of Determinative Bacteriology including indole production test, citrate utilization test, oxidase test, catalase test, starch hydrolysis, casein hydrolysis, and carbohydrate fermentation test performed to check the biochemical characteristics of producing strain [28]. Using an inoculating needle a colony was taken aseptically and put onto a clean slide and heat fixed. Crystal violet was added on the slide and allowed to stand for $60 \mathrm{sec}$ and washed with distilled water. Gram's Iodine was added and left for $30 \mathrm{sec}$ then the decolourizer was added appropriately till it became light violet [29]. Safranine was added on the slide and allowed to stand for $1 \mathrm{~min}$, and the slide was washed with distilled water. Slide was air dried and observed under the light as well as electron microscope. Besides it was tested to determine whether the unknown bacterium was acid-fast.

For accomplishing antibiotic assay using well technique nutrient agar medium was prepared and sterilized and poured into Petri plates under aseptic conditions in a Laminar air flow. The Petri plates were kept for setting of medium for about $10 \mathrm{~min}$ and the wells were made at selected areas in Petri plates [29]. Thenafter the test organism's micrococcus and the bacillus strains were swabbed on the Petri plates with a sterile swab and left for $10 \mathrm{~min}$. The crude extract obtained from centrifugation of production medium was aspirated and loaded into the wells with the capacity of $100 \mu \mathrm{l}$ each. The Petri plates were incubated overnight with out inverting at optimum temperature of $37^{\circ} \mathrm{C}$ for 24 hours [30]. The comparison of inhibitory strains were monitored carefully and checked for the increasing concentrations of the antibiotic with effect to the increasing concentrations of the sodium nitrate [31].

\section{RESULTS AND DISCUSSION}

The Streptomyces flora of 9 soil samples, collected from different locations in the Kanpur Industrial areas Kanpur, India, were screened for their potential as a source of antibiotics active against antibiotic resistant bacteria. All of the isolates were tested for their ability to produce inhibitory substances against seven test microorganisms (Fig. 1). The results obtained showed similarties to those reported in the earlier studies [13, 32, 33] The test microorganisms included 3 Gram positive bacteria, 3 Gram negative bacteria and 1 yeast. Of them $S$. aureus and $S$. maltophilia were resistant to the widely used antibiotics (Table $\mathbf{1}$ ). The isolates which exhibited antimicrobial activity against the test organisms have shown the resemblance to that reported in previous studies [34-37]. Six bacteria, including three Gram positive organisms were selected for this study. The morphological examination of these isolates, which were active on the test organisms, was observed to reflect that these belong to the Streptomyces genus. Gram positive forming bacilli were keenly observed. Strain was found contaminated. The enhancement in the potentiality of antibiotics i.e antimicrobial activity could be only due to exogenous incorporation of metal ions as well as complex compounds based on sodium, potassium, calcium, magnesium and phosphorus in different sets of experiments and cumulative effect of all together is reported Table $\mathbf{1}$. 

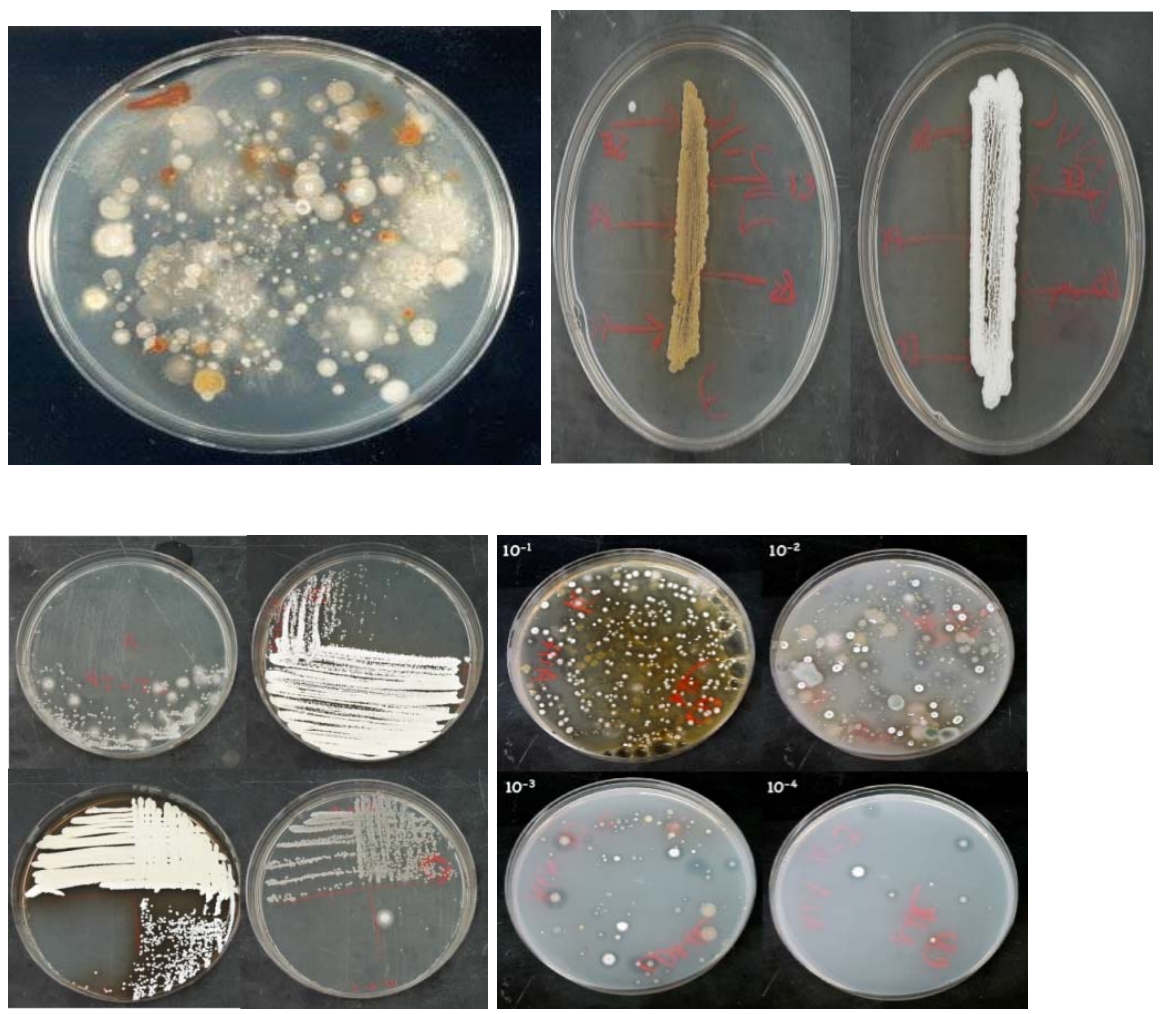

Fig. (1). Disk diffusion method or Kirby-Bauer antibiotic sensitivity test. Picture showing the growth of gram positive as well as gram negative bacterial and fungal isolates from soil sample from certain industrial areas.

Table 1. Optimization of Potentiality Antibiotic. The Data were Summarized as the Cumulative Induction of Ions Such as: Sodium, Potassium, Calcium, Magnesium and Phosphorus

\begin{tabular}{|c|c|}
\hline Concentration of $\mathrm{NaNO}_{3}$ & Zone of Inhibition \\
\hline \hline $0.8 \%$ & $1 \mathrm{~cm}$ \\
\hline $1 \%$ & $1.1 \mathrm{~cm}$ \\
\hline $1.2 \%$ & $1.4 \mathrm{~cm}$ \\
\hline $1.4 \%$ & $0.9 \mathrm{~cm}$ \\
\hline
\end{tabular}

It is quite interesting to discuss the impact of exogenous supplementation of metal ions as well as complex compounds based on certain specific metal ions and minerals, on the growth of microbial organism (bacteria and fungi) as well as upscaling production of antibiotics from these organisms. In this reference the work accomplished in the preceding decade $[8,38]$ can be taken into consideration to justify the data obtained from the present study. Accordingly The levels of calcium and iron content of the mono-culture fermented mango kernel cake was observed to reflect added values to the mineral nutritional quality, as calcium being an essential factor for building living cells making up an animal body [38]. The quantity of magnesium recorded may still be adequate for animal nutrition since its help in keeping the muscles relaxed and used for the formation of strong bones and teeth in addition to controlling blood pressure and nerve transmitter [38]. Besides, the values of potassium, sodium, magnesium and other metal ions and minerals in most of the fermented mango kernel cakes may be adequate for animal feeding; thereby preventing the danger of muscular paralysis, mental disorientation and cardiac irregularities often associated with a fall in the level of potassium in the plasma. However, the levels of the individual essential amino acid of the fermented MKC suggested that there is still need for adequate supplementation of lysine and methionine, critically important for proper growth and development of poultry when the mono-culture fungal fermented MKC is to be used as chicken's feedstuff. Finally taken together the present study and the data reported in the previous reports [8, 38-40], the mono-culture of fungal and bacterial isolates applying towards production of antibiotics would certainly be quantitatively as well as qualititatively much more upgraded as a consequence of cumulative induction by certain specific metal ions and minerals. If those are present in the source soil, the isolation of microbes followed by standardization of antibiotic production should be carried out at the routine basis, but if it is contrary, the adequate supplementation of essential metal ions/minerals is quite mandatory for microbiologists to work along these notions and objectives in future. 


\section{CONCLUSION}

The soil microbial isolate isolated was showing antibiotic activity under normal growth conditions and was found inhibiting the gram positive bacilli and cocci. Crude extract of the microbial culture was proved showing the inhibition, which is further purified by the solvent extraction procedure .Sodium nitrate in increasing concentrations was found to have an enhancing effect on the bacterial antibiotic activity, but high concentrations that is more than $1.2 \%$ was found detrimental. At $1.4 \%$ the activity was found less inferring the effect of high concentrations of sodium nitrate in antibiotic production. Gram positive strains being more resistant because of their resistant spore formation were very hard to control. This work may provide an helpful information on the bacterial strain application in the industrial production of antibiotic that can easily control the gram positive strains. As the strain was a soil isolates its isolation, culturing and industrial exploitation aspects will be very easy to control. We suggest the strain improvement by the mutagenic agents and exogenous supplementation of certain specific metal ions and/or minerals to the microbial culture media probably being of great significance in view of enhancing the antibiotic activity. Besides, extraction and purification methods can be further employed for the pure antibiotic extraction.

\section{ACKNOWLEDGEMENTS}

The present paper is a piece of Ph.D. work of author, APS, registered at IFTM University, Moradabad, Uttar Pradesh, India.

\section{CONFLICT OF INTEREST}

The authors confirm that this article content has no conflicts of interest.

\section{REFERENCES}

[1] Thomson JM, Bonomo RA. The threat of antibiotic resistance in Gram-negative pathogenic bacteria: Beta-lactams in peril! Curr Opin Microbiol 2006; 8: 518-24.

[2] Wilke MS, Lovering AL, Strynadka NC. Beta-Lactam antibiotic resistance: a current structural perspective. Curr Opin Microbiol 2007; 8: 525-33.

[3] Hansen LH, Ferrari B, Sorensen AH, et al. Detection of oxytetracycline production by Streptomyces rimosus in soil microcosms by combining whole-cell biosensors and flow cytometry. Appl Environ Microbiol 2006; 67: 239-44.

[4] Goldstein DA, Tinland B, Gilbertson LA, et al. Human safety and genetically modified plants: A review of antibiotic resistance markers and future transformation selection technologies. J Appl Microbiol 2005; 99: 7-23.

[5] Badosa E, Moreno C, Montesinos E. Lack of detection of ampicillin resistance gene transfer from Bt176 transgenic corn to culturable bacteria under field conditions. FEMS Microbiol Ecol 2004; 48: 169-78.

[6] Collatz E, Tran Van Nhieu G, Billot-Klein D, et al. Substitution of serine for arginine in position 162 of tem-type beta-lactamases extends the substrate profile of mutant enzymes, tem-7 and tem-101, to ceftazidime and aztreonam. Gene 2007; 78: 349-54.

[7] Rasche F, Hödl V, Poll C, et al. Rhizosphere bacteria affected by transgenic potatoes with antibacterial activities compared with the effects of soil, wild-type potatoes, and vegetation stage and pathogen exposure. FEMS Microbiol Ecol 2006; 56: 219-35.

[8] Kayode RMO, Sani A. Physicochemical and proximate composition of mango (Mangifera indica) kernel cake fermented with mono-culture of fungal isolates obtained from naturally decomposed mango kernel. Life Sci J 2008; 5(4): 55-63.
Saif YM. Essential inorganic elements. In: Diseases of poultry. Chapter 30, 11 ed. USA: Iowa State University Press 2003; p. 1231

[10] Kolawole OM, Kayode RMO, Akinduyo BK. Proximate and microbial analyses of burukutu and pito produced in Ilorin, Nigeria. Afr J Biotechnol 2007; 6: 587-90.

[11] Mudgal V, Madaan N, Mudgal A, Singh RB, Mishra S. Effect of toxic metals on human health. Open Nutra J 2010; 3: 94-9.

[12] Mishra S, Dwivedi SP, Singh RB. A review on epigenetic effect of heavy metal carcinogens on human health. Open Nutra J 2010; 3: 188-93.

[13] Singh AP, Singh RB, Mishra S. Microbial and biochemical aspects of antibiotic producing microorganisms from soil samples of certain industrial area of India- An Overview. Open Nutra J 2012; 5 : 107-12.

[14] Schmalenberger A, Tebbe CC. Genetic profiling of noncultivated bacteria from the rhizospheres of sugar beet (Beta vulgaris) reveal field and annual variability but no effect of a transgenic herbicide resistance. Can J Microbiol 2005; 49:1-8.

[15] Bertrand H, Poly F, Van VT, et al. High molecular weight DNA recovery from soils prerequisite for biotechnological metagenomic library construction. J Microbiol Methods 2005; 62: 1-11

[16] Kay E, Vogel TM, Bertolla F, Nalin R, Simonet P. In situ transfer of antibiotic resistance genes from transgenic (transplastomic) tobacco plants to bacteria. Appl Environ Microbiol 2002; 68: 334551.

[17] Weller DM, Raaijmakers JM, Gardener BBM, Thomashow LS Microbial populations responsible for specific soil suppressiveness to plant pathogens. Annu Rev Phytopathol 2002; 40: 309-48.

[18] Evanylo GK, Alley MM. Pressidedress soil nitrogen test for corn in Virginia. Commun Soil Sci Plant Anal 1997; 28: 1285-301.

[19] Dick RP, Thomas DR, Halvorson JJ. Standardized methods, sampling, and sample pretreatment. In: Doran JW, Jones AJ, Eds. Methods for assessing soil quality. SSSA Spec. Publ. 49. Madison, Wisconsin, USA: Soil Science Society of America, Inc: 2007; pp. 107-22.

[20] Hammer KA, Carson CF, Riley TV. Susceptibility of transient and commensal skin flora to the essential oil of Melaleuca alternifolia (tea tree oil). Am J Infect Control 2002; 24(3): 186-9.

[21] National Committee for Clinical Laboratory Standards. Performance Standards for Antimicrobial susceptibility testing. $8^{\text {th }}$ Informational Supplement. M100 S12. Wayne, PA: National Committee for Clinical Laboratory Standards, 2002.

[22] Water worth PM. Quantitative methods for bacterial sensitivity testing. In: Reeves DS, Philips I, Williams JD, Wise R, Eds. Laboratory methods in antimicrobial chemotherapy. Edinburgh: Churchill Livingstone 1978; pp. 31-41.

[23] Lalitha MK, Manayani DJ, Priya L, Jesudason MV, Thomas K, Steinhoff MC. E test asan alternative to conventional MIC determination for surveillance of drug resistant S. pneumoniae. Indian J Med Res 1997; 106: 500-3.

[24] John DT, James HJ. Antimicrobial susceptibility testing: General considerations. In: Murray PR, Baron EJ, Pfaller MA, Tenover FC, Yolken R, Eds. Manual of clinical microbiology. $7^{\text {th }}$ ed. Washington DC: American Society for Microbiology 1999; pp. 1469-73.

[25] Anonymous. A guide to sensitivity testing: Report of working party on antibiotic sensitivity testing of the British Society for Antimicrobial Chemotherapy. J Antimicrob Chemother 2006; 27(D): 150 .

[26] Jorgensen JH, Ferraro MJ. Antimicrobial susceptibility testing: a review of principles and contemporary practices. Clin Infect Dis 2009; 49(11): 49-55.

[27] Doern G.V. Susceptibility tests of fastidious bacteria. In: Murray PR, Baron EJ, Pfaller MA, Tenover FC, Yolken R, Eds. Manual of Clinical Microbiology. $6^{\text {th }}$ ed. Washington DC: American Society for Microbiology 1995; pp. 1342-9.

[28] Alexander TW, Yanke LJ, Topp D, et al. Effect of Sub Therapeutic administration of antibiotics on the prevalence of antibioticresistant Escherichia coli bacteria in feedlot cattle. Appl Environ Microbial 2005; 74: 4405-16.

[29] Arshad MA, Lowery B, Grossman B. Physical tests for monitoring soil quality. In: Doran JW, Jones AJ, Eds. Methods for assessing soil quality. SSSA Spec. Publ. 49. Madison, Wisconsin, USA: Soil Science Society of America, Inc: 2007; pp. 123-42. 
[30] Haque SFK, Sen SK, Pal SC. Screening and identification of antibiotic producing strains of Streptomyces. Hindustan Antibiot Bull 2008; 3-4: 76-83.

[31] Augustine SK, Bhavsar SP, Baserisaleni M, Kapadnis BP. Isolation, Characterization and optimization of antifungal activity of an actinomycete of soil Origin. Indian J Exp Biol 2009; 42: 928-32.

[32] Acebal C, Alcazar R, Canedo M, Rodringuez P, Romero F, Frenandez JL. Two marine Agrobacterium producers of sesbanimide antibiotics. J Antibiot 2007; 51(1): 64-7.

[33] Botole R, Spera S, Guglielmetti G, Cassani G. AB023, Novel polyene antibiotics. II- Isolation and structure determination. J Antibiot 2006; 46(2): 255-64.

[34] Jenssen WD, Thakker-Varia S, Dubin DT, Weinstein MP. Prevalence of macrolides-lincosamides streptogramin B resistance and erm gene classes among clinical strains of staphylococci and streptococci. Antimicrob Agents Chemother 2006; 31: 883-8.
[35] Ahmad S, Akhter M, Zia-Ul- Haq M, Mehjabeen, Ahmed M. Antifungal and nematicidal activity of selected legumes of Pakistan. Pak J Bot 2010; 42(2): 1327-31.

[36] Jahan N, Ahmed M, Mehjabeen, Zia-Ul-Haq M, Alam SM, Qureshi M. Antimicrobial screening of some medicinal plants of Pakistan. Pak J Bot 2010; 42(6): 4281-4.

[37] Zia-Ul-Haq M, Ahmed M, Jahan N, et al. Antimicrobial screening of selected flora of Pakistan. Arch Biol Sci 2011; 63(3): 691-5.

[38] Thomas D. A textbook of biochemistry with clinical correlations. $5^{\text {th }}$ ed. NY: John Willey and Sons, Inc publication 2002; pp. 115960.

[39] Mishra S, Singh RB, Dwivedi SP, et al. Effects of nutraceuticals on genetic expressions. Open Nutra J 2009; 2: 70-80.

[40] Mishra S, Nanda S, Madaan N, Mudgal V. Studies on production of alcoholic beverages from some tropical fruits. Open Nutra $\mathrm{J}$ 2010; 3: 184-7.

(C) Singh et al.; Licensee Bentham Open.

This is an open access article licensed under the terms of the Creative Commons Attribution Non-Commercial License (http://creativecommons. org/licenses/ by-nc/3. 0/) which permits unrestricted, non-commercial use, distribution and reproduction in any medium, provided the work is properly cited. 